\title{
Predictive analytics for the Vipulanandan rheological model and its correlative effect for nanoparticle modification of drilling mud.
}

\author{
AFOLABI, R.O., YUSUF, E.O., OKONJI, C.V., NWOBODO, S.C.
}




\section{Journal Pre-proof}

Predictive analytics for the Vipulanandan rheological model and its correlative effect for nanoparticle modification of drilling mud

Richard O. Afolabi, Esther O. Yusuf, Chude V. Okonji, Shalom C. Nwobodo

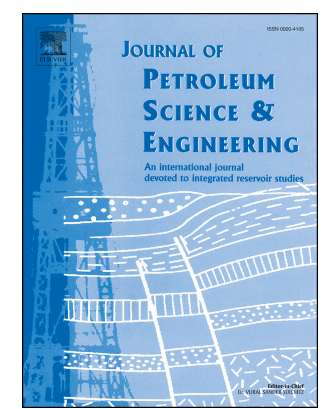

PII: S0920-4105(19)30798-3

DOI: https://doi.org/10.1016/j.petrol.2019.106377

Reference: PETROL 106377

To appear in: Journal of Petroleum Science and Engineering

Received Date: 16 March 2019

Revised Date: 12 July 2019

Accepted Date: 12 August 2019

Please cite this article as: Afolabi, R.O., Yusuf, E.O., Okonji, C.V., Nwobodo, S.C., Predictive analytics for the Vipulanandan rheological model and its correlative effect for nanoparticle modification of drilling mud, Journal of Petroleum Science and Engineering (2019), doi: https://doi.org/10.1016/ j.petrol.2019.106377.

This is a PDF file of an article that has undergone enhancements after acceptance, such as the addition of a cover page and metadata, and formatting for readability, but it is not yet the definitive version of record. This version will undergo additional copyediting, typesetting and review before it is published in its final form, but we are providing this version to give early visibility of the article. Please note that, during the production process, errors may be discovered which could affect the content, and all legal disclaimers that apply to the journal pertain.

(C) 2019 Published by Elsevier B.V. 


\section{Research Article}

2 Title: Predictive Analytics for the Vipulanandan Rheological Model and its Correlative

3 Effect for Nanoparticle Modification of Drilling Mud.

4 Authors: Richard O. Afolabi 1, 3, *, Esther O. Yusuf ${ }^{2}$, Chude V. Okonji ${ }^{3}$, Shalom C.

$5 \quad$ Nwobodo $^{3}$

6 Affiliations: ${ }^{1}$ School of Engineering, Robert Gordon University, Aberdeen, AB10 7GJ,

$7 \quad$ United Kingdom

$8{ }^{2}$ Department of Chemical Engineering, Covenant University, P.M.B 1023, Ota, Ogun State,

$9 \quad$ Nigeria.

$10{ }^{3}$ Department of Petroleum Engineering, Covenant University, P.M.B 1023, Ota, Ogun State,

11 Nigeria.

*Contact email: r.afolabi@rgu.ac.uk; richard.afolabi@ covenantuniversity.edu.ng 


\section{Abstract}

22

Modelling the flow of nanoparticle modified drilling mud (or nano-drilling muds) requires the use of existing generic time-independent models with the addition of nanoparticle terms having a number of parameters incorporated. These parameters quantify the uncertainties surrounding nanoparticle contributions to drilling mud rheology. However, when the parameters in the overall model become too large, the tuning of each parameter for proper flow description can be challenging and time-consuming. In addition, the predictive capability of known models for the different regimes associated with the flow of nanodrilling muds is limited in scope and application. For example, computational analysis involving nano-drilling muds have been described using Herschel-Buckley, Power-Law, Bingham Plastic, Robertson-Stiff, Casson, Sisko, and Prandtl-Eyring. However, these models have been shown over time to have limited predictive capability in accurately describing the flow behavior over the full spectrum of shear rates. Recently, a new rheological model, the Vipulanandan model, has gained attraction due to its extensive predictive capability compared to known generic time-independent models. In this work, a rheological and computational analysis of the Vipulanandan model was carried out with specific emphasis on its modification to account for the effects of nanoparticles on drilling muds. The outcome of this novel approach is that the Vipulanandan model can be modified to account for the effect of interaction between nanoparticles and clay particles. The modified Vipulanandan show better prediction for a $6.3 \mathrm{wt} . \%$ mud with $\mathrm{R}^{2}$ of 0.999 compared to 0.962 for Power law and 0.991 for Bingham. However, the $\mathrm{R}^{2}$ value was the same with Herschel Buckley model but the RMSE value show better prediction for the Vipulanandan model with a value of $0.377 \mathrm{~Pa}$ compared to the 0.433 Pa for Herschel Buckley model.

Keywords: Drilling Mud; Bentonite Mud; Vipulanandan; Nanoparticles; Rheology, Modelling 
47

48

49

50

51

52

53

54

55

56

57

58

59

$60 \quad \frac{\mathrm{d} \tau}{\mathrm{d} \dot{\gamma}}>0$

$61 \quad \frac{\mathrm{d}^{2} \tau}{\mathrm{d} \dot{\gamma}^{2}}<0$

62

63

64 Where $\tau_{0}$ is the yield point, $\tau$ is the shear stress and $\dot{\gamma}$ is the shear rate of the drilling mud.

65

66

67

68

\section{Introduction}

The description of the rheology of drilling muds is essential for an adequate determination of hydraulic conditions such as velocity profile and pressure loss emanating during drilling activities (Toorman, 1997). This is also significant in the estimation of the hole cleaning efficiency of the drilling mud (Toorman, 1997; Abdo and Danish Haneef, 2012; Hoelscher et al., 2012; Jung et al., 2013; Ismail et al., 2016; Afolabi et al., 2017a). Therefore, computational modelling of the velocity profile, pressure loss and hole cleaning efficiency during drilling requires models which can approximate the rheology of the mud. The application of known rheological models in the description of the flow behavior of drilling muds necessitates that its predictive capability correlates with certain conditions. Mathematically, Vipulanandan and Mohammed (2014) described these conditions as shown in equations (1) to (4):

$\lim _{\dot{\gamma} \rightarrow 0} \tau=\tau_{0}$

$\lim _{\dot{\gamma} \rightarrow \infty} \tau=\tau_{\max }$

Equation (1) simply describes the yield point of the drilling mud. This is the minimum shear stress that must be exceeded for the drilling mud to flow. Furthermore, it is a measure of the pumping ability of the drilling mud and its efficiency in the removal of drilled cuttings under static and dynamic conditions respectively (Kelessidis and Maglione, 2008; Abu-Jdayil, 
2011; Lee et al., 2012; Yoon and El-Mohtar, 2013; Vipulanandan and Mohammed, 2014;

Afolabi et al., 2017a; Afolabi and Yusuf, 2018). In addition, equation (2) indicates that the drilling mud must possess sufficient viscosity in order to keep the weighting materials and drilled cuttings suspended during continuous mud circulation. The absence of sufficient viscosity would result in the cuttings or weighting materials settling out of suspension when mud circulation is stopped (Fazelabdolabadi et al., 2015; Ismail et al., 2016; Afolabi et al., 2017a; Afolabi et al., 2017b; Afolabi and Yusuf, 2018). The thixotropic nature of drilling muds is captured in equation (3) where there is a reversible decrease in viscosity with shear rate and increase in viscosity when the shear is removed. Moreover, the maximum shear stress tolerance of the drilling mud is captured in equation (4). The shear stress limit of a drilling mud indicates its erosive capability which is an important function of drilling muds (Vipulanandan and Mohammed, 2014; Afolabi et al., 2017b; Afolabi and Yusuf, 2018). Asides the breaking of rocks by the drill bit, the drilling muds must also contribute to this through its erosive potential. Accordingly, the need for an efficient drilling mud system made from bentonite suspensions has resulted in research into nanotechnology (Zakaria et al., 2012; Mahmoud et al., 2016; Afolabi et al., 2017b; Afolabi and Yusuf, 2018). However, computational modelling of nanoparticle effect on the flow behavior of drilling mud is still limited in scope and application with reliance placed on existing models such as HerschelBuckley, Power-Law, Bingham Plastic, Robertson-Stiff, Casson, Sisko, and Prandtl-Eyring. In addition, generic rheological models used in the petroleum industry would give a generalized approach to computing the performance of nano-drilling muds without adequately capturing contributions due to nanoparticles (Reilly et al., 2016; Afolabi et al., 2017a; Afolabi et al., 2017b; Afolabi and Yusuf, 2018; Gerogiorgis et al., 2017; Vryzas and Kelessidis, 2017). Consequently, the use of existing time independent rheological models in its present form for nano-drilling muds would require a data-driven approach where models 
94 are regressed to shear stress-shear rate values. Nevertheless, Reilly et al. (2016) and

95 Gerogiorgis et al. (2017) derived a multivariate rheological model from first principles which

96

97

describe the flow behavior of nanoparticle modified drilling muds. The shear stress of the nano-drilling mud was dependent on the volume fraction of nanoparticles, size of nanoparticles and shear rate with good correlation at high shear rates. The multivariate model developed by the authors followed the expression in equation (5):

$\tau=\tau_{y}+\tau_{\infty}+\tau_{n p}$

where $\tau_{\mathrm{y}}$ is the yield stress of the mud, $\tau_{\mathrm{np}}$ is the shear stress of the mus due to nanoparticles and $\tau_{\infty}$ is the shear stress ascribed to the constant viscosity of a drilling mud measured at high shear rates. Equation (6) shows the model derived by the authors by applying the expression in (5):

$\tau=\tau_{y}+\mu_{\infty} \gamma+\frac{\mathrm{A}_{\mathrm{o}} \mathrm{r}_{\mathrm{p}}}{12 \mathrm{~A}_{\mathrm{p}}\left[4 \mathrm{r}_{\mathrm{p}}\left(\frac{1}{1+\beta \dot{\gamma}}\right)+\left(1-\frac{1}{1+\beta \dot{\gamma}}\right) \mathrm{d}_{\mathrm{p}} \sqrt[3]{\frac{\pi}{6 \varnothing}}\right]^{2}}$

Where $A_{o}$ is the Hamaker constant, $A_{p}$ is the area of nanoparticles, $r_{p}$ is the radius of nanoparticles, $d_{p}$ is the diameter of the nanoparticles, $\phi$ is the volume faction of nanoparticles and $\beta$ is a time constant. This modelling approach for nano-drilling mud is simply the addition of the Bingham plastic model with a term for nanoparticle. Equally, the modelling approach means that it is limited to a specific model (Bingham plastic model) and may not accurately describe the flow behaviour over the full spectrum of shear rates as indicated by (1) to (4). Nonetheless, the multi-parameter nature of the model generally would give a full description of the contribution of nanoparticles to drilling mud rheology. Table 1 show some specific rheological models and their predictive capability based on the conditions represented in equations (1) to (4). Based on these conditions, the Vipulanandan model proposed by Vipulanandan and Mohammed (2014) has a good predictive capability in 
accurately describing the flow behaviour over the full spectrum of shear rates. In this work, the Vipulanandan model was modified to account for the effect of nanoparticles. The development of the shear term for nanoparticles flowed the procedure given by Reilly et al. (2016) and Gerogiorgis et al. (2017). However, the term for nanoparticles was modified in order to reduce the complexity of the resultant model for the purpose of regression analysis.

The outcome of this novel approach is that the Vipulanandan model can be modified to account for the effect of interaction between nanoparticles and clay particles. This was achieved by considering the Hamaker constant in the modified Vipulanandan model as a tuning parameter. In addition, other effects such as temperature and salinity were captured without necessarily introducing new fitting parameter.

\section{Modification of the Vipulanandan Model}

\subsection{Dimensionless Structuring Term}

According to Toorman (1997), a dimensionless structuring parameter, $\lambda$ can be used to describe the changing structure of cohesive sediment suspension such as drilling muds under varying shear rates, $\dot{\gamma}$. This expression is given below in (7) and it is obtained under a pseudo-equilibrium state.

$133 \lambda=\frac{1}{1+\beta_{i} \dot{\gamma}}$

Where $\beta_{i}$ is a time constant which is a ratio of the thickening and thinning parameters of the fluid suspension.

\subsection{Vipulanandan Model and Dimensionless Structuring Term}

137 The Vipulanandan model proposed by Vipulanandan and Mohammed (2014) which has a 138 limit on the shear stress for a drilling mud was considered among others for this study as 139 shown in equation (8) below 
$140 \tau=\tau_{0}+\frac{\dot{\gamma}}{\mathrm{A}+\mathrm{D} \dot{\gamma}}$

141 Where $\dot{\gamma}$ is the shear rate $\left(\mathrm{s}^{-1}\right), \tau_{0}$ is the yield stress $(\mathrm{Pa}), \mathrm{A}\left([\mathrm{Pas}]^{-1}\right)$ and $\mathrm{D}\left(\mathrm{Pa}^{-1}\right)$ are

142 model parameters or constants respectively. The shear erosive potential of the drilling mud

143 can be predicted by its shear stress limit, $\tau_{\lim }$ according to equation (9).

$144 \lim _{\gamma \rightarrow \infty} \tau=\tau_{\lim }=\tau_{0}+\frac{1}{\mathrm{D}}$

145 The ratio of the model constants (D/A) represents a time constant denoted $\beta_{1}$ and this can be 146 represented as shown in (10)

$147 \quad \beta_{1}=\frac{\mathrm{D}}{\mathrm{A}}$

148 Modifying equation (8) to take into account this time constant yields equation (11) with

$149 \beta_{2}=1 / \mathrm{A}(\mathrm{Pas})$.

$150 \tau=\tau_{0}+\frac{\beta_{2} \dot{\gamma}}{1+\beta_{1} \dot{\gamma}}$

151 Comparing (11) with (7) yields

$152 \tau=\tau_{0}+\lambda \beta_{2} \dot{\gamma}$

153 This indicates that the Vipulanandan model has dimensionless structuring term which

154 explains how the drilling mud structure changes monotonically from its initial state under 155 zero shear rate to a final state under an infinite shear rate.

\subsection{Nanoparticle Modified Vipulanandan Model}

157 According to Reilly et al. (2016) and Gerogiorgis et al. (2017), the maximum interparticle

158 distance between nanoparticles, $\mathrm{H}$ can be expressed as a function of the size of the nanoparticle, $d_{p}$ and volume fraction of nanoparticles, $\phi$ 
$160 \quad \mathrm{H}=\mathrm{d}_{\mathrm{p}} \sqrt[3]{\frac{\pi}{6 \phi}}$

161 However, in this work, $\mathrm{H}$ is considered the interparticle distance between nanoparticles in the

162 presence and absence of shear. This can be related to the van der Waals force of attraction

163 between nanoparticles as shown below (14).

$164 \quad F_{v d w}=\frac{\mathrm{A}_{\mathrm{o}} \mathrm{r}_{\mathrm{p}}}{12[\mathrm{H}]^{2}}$

$165 \mathrm{~A}_{\mathrm{o}}$ is the Hamaker constant which provides the means to determine the interaction between

166 particles. In order to understand how the van der Waals force of attraction between

167 nanoparticles change under shear rates, the dimensionless structuring term is incorporated as

168 follows

$169 \quad F_{v d w}=\frac{\mathrm{A}_{\mathrm{o}} \mathrm{r}_{\mathrm{p}}}{12[\mathrm{H}]^{2}}\left(\frac{1}{1+\beta_{3} \dot{\gamma}}\right) \equiv \frac{\mathrm{A}_{\mathrm{o}} \mathrm{r}_{\mathrm{p}}}{12[\mathrm{H}]^{2}\left(1+\beta_{3} \dot{\gamma}\right)}$

170 Substituting for $\mathrm{H}$,

$171 \quad F_{v d w}=\frac{\mathrm{A}_{\mathrm{o}}}{48 \mathrm{r}_{\mathrm{p}}\left[\frac{\pi}{6 \phi}\right]^{2 / 3}\left(1+\beta_{3} \dot{\gamma}\right)}$

172 Therefore, the shear stress due to nanoparticles, $\tau_{\mathrm{np}}$ can be expressed as the van der Waals

173 force per unit nanoparticle area, $A_{p}$.

$174 \quad \tau_{\mathrm{np}}=\frac{\mathrm{A}_{\mathrm{o}}}{48 \mathrm{~A}_{\mathrm{p}} \mathrm{r}_{\mathrm{p}}\left[\frac{\pi}{6 \phi}\right]^{2 / 3}\left(1+\beta_{3} \dot{\gamma}\right)}$

175 Therefore, the modified form of the Vipulanandan model incorporating the effect of

176 nanoparticles is given in (18)

$177 \tau=\tau_{0}+\frac{\beta_{2} \dot{\gamma}}{1+\beta_{1} \dot{\gamma}}+\frac{\mathrm{A}_{\mathrm{o}}}{48 \mathrm{~A}_{\mathrm{p}} \mathrm{r}_{\mathrm{p}}\left[\frac{\pi}{6 \phi}\right]^{2 / 3}\left(1+\beta_{3} \dot{\gamma}\right)}$ 
In order to account for the interaction between nanoparticles and bentonite clay, equation (18)

179

180

181

is modified to have a tuning parameter, $\beta_{o}$

$\tau=\tau_{0}+\frac{\beta_{2} \dot{\gamma}}{1+\beta_{1} \dot{\gamma}}+\frac{\beta_{o}}{\left(1+\beta_{3} \dot{\gamma}\right)}$

Where $\beta_{o}=\left(\mathrm{A}_{\mathrm{o}} /\left[48 \mathrm{~A}_{\mathrm{p}} \mathrm{r}_{\mathrm{p}}\left[\frac{\pi}{6 \phi}\right]^{2 / 3}\right]\right)$ with units of Pa. This tuning parameter accounts for the uncertainty relating to the dispersion of nanoparticles and the assumption of spherical size for the nanoparticles. In addition, the value of $\beta_{o}$ will change due to variation in the surface properties of the nanoparticles due to interaction with bentonite clay in drilling muds. This parameter would account for the contribution of these interactions to the shear stress profile of the drilling mud. The interaction between the nanoparticles and bentonite clay is assumed to be more of a physical interaction and as such, the prospects of a chemical reaction occurring is neglected. $\beta_{3}$ is considered a characteristic time constant associated with the interaction between clay and nanoparticles.

\section{Material and Methods}

\subsection{Materials}

The materials used in the study include commercial bentonite clay and silica nanoparticles (appearance: powder; colour: white; surface area: $60.2 \mathrm{~m} / \mathrm{g}$, purity: $99.8 \%$, size: $50 \pm 4 \mathrm{~nm}$ ), which were purchased in Nigeria. Silica nanoparticles was considered due to its low toxicity and scalable availability arising from surface functionalization (Liberman et al., 2014).

\subsection{Formulation of Nanoparticle Modified Drilling Mud}

The preparation of nanofluids was done in different concentrations containing $0.2,0.4$, and 0.6 vol.\% of silica nanoparticles dispersed in $400 \mathrm{~mL}$ of deionized water respectively. A Hamilton beach mixer was used to continuously stir the nanoparticle dispersions until the formation of silica nanofluids. The nanofluids were the medium for dissolution of bentonite 
201

202

203

204

205

206

207

208

209

210

211

212

213

214

215

216

217

218

219

220

221

222

223

224

clays thereby giving rise to nano-drilling muds. The stirring speed of the mixer was set to 11000-RPM. The nano-drilling mud was prepared by adding $6.3,13$ and $15 \mathrm{wt} . \%$ of bentonite clay to different concentrations of nanofluids followed by mixing for 20 minutes. Subsequent nano-drilling mud was prepared by increasing the bentonite content.

\subsection{Rheological Measurement}

The flow characteristics of the nano-drilling mud were evaluated using an OFITE Model 800 (8-Speed) Viscometer that is manufactured by OFI Testing Equipment, Inc. The rheological behavior was obtained by measuring the shear stress at different shear rates. The shear rates were simply altered with a speed regulator, which was done to sustain a continuous shear rate under changing shear conditions and input power. The values for shear stress were shown on an illuminated enlarged dial for easy reading. The dial readings (DR) from the viscometer were taken at equilibrium values. The eight accurately controlled test speeds of the viscometer (shear rates in RPM) are 3 (Gel), 6, 30, 60, 100, 200, 300, and 600.

\section{Results and Discussion}

\subsection{Comparison between Vipulanandan and other Rheological Models}

Comparison between the Vipulanandan model in equation (11) and the 2 most common rheological models (Bingham and Herschel Buckley) employed in the oil and gas industry is shown in Figure 1. For the Bingham Plastic model, the $R^{2}$ value of 0.991 and RMSE value of $1.039 \mathrm{~Pa}$ was obtained for $6.3 \mathrm{wt} . \%$ bentonite mud. In the case of the Herschel Buckley model, the base case mud of 6.3 wt.\%, bentonite content was modelled with, $R^{2}$ value of 0.999 and RMSE value of 0.433 Pa respectively. The Vipulanandan model with shear stress limit prediction was fitted with a $R^{2}$ value of 0.999 and RMSE value of $0.377 \mathrm{~Pa}$ for 6.3 wt.\% bentonite mud. The Vipulanandan and Herschel Buckley models showed comparable values for $R^{2}$. However, the RMSE value for the Vipulanandan model was lower $(0.377 \mathrm{~Pa})$ 
compared to the Herschel Buckley model $(0.433 \mathrm{~Pa})$. This indicates a better fitting of the

Vipulanandan model to the rheological data. Further comparison between the Vipulanandan and Herschel Buckley models was done using the confidence and prediction intervals. Figure 2 show the $95 \%$ confidence interval for the Vipulanandan and Herschel Buckley models. The tapered confidence interval connected with the models is suggestive of their accuracy in predicting the shear stress for a definite set of the predictor variable which is the shear rate. Furthermore, in accessing the applicability of the Vipulanandan model, the uncertainty of predicting the value of a single future observation or a fixed number of multiple future observations based on the distribution of previous observations was evaluated. This was done using the prediction interval, which is the range that is likely to contain a single future response for a selected combination of variable settings. Figure 3 show the $95 \%$ prediction interval for the Vipulanandan and Herschel Buckley models. There is a $95 \%$ probability that future observation will be contained within the prediction interval. Therefore, the Vipulanandan model shows comparable fitting attributes with the Herschel Buckley rheological model employed in the oil and gas industry. However, the capability of the Vipulanandan model is extended above the Herschel Buckley model due to its prediction of the shear stress limit.

\subsection{The Effect of Bentonite Content at given Nanoparticle Concentration}

Figure 4 shows the fitted modified Vipulanandan model (equation 19) to a drilling mud containing 13 and 15 wt.\% bentonite clay and 0.2 vol.\% silica nanoparticles. The model shows good fitting to the rheological data irrespective of the bentonite clay content. The model time constant, $\beta_{3}$ and tuning parameter, $\beta_{0}$ for the varied bentonite content is shown in Table 2. The trend with bentonite content associated with the time constant and tuning parameter are captured in Figure 5. The tuning parameter is assumed to account for the dispersion and the level of interaction of particles arising from hydration in water. In 
addition, the trend of the increase in the value of the tuning parameter show that the large amount of clay particles may envelop the contribution of nanoparticles to the rheology of the drilling mud. This is obvious from Figure 5(a) and it can be seen that beyond the bentonite content of $13 \mathrm{wt} . \%$, there is a rapid increase in the value of the tuning parameter. In this case, the interaction between clay particles dominate the rheology of the nano-modified drilling mud. This is apparent due to the large size of the clay particles compared to the silica nanoparticles. The rise in the value of the time constant, $\beta_{1}$ (Table 2) explains the increased interaction between clay particles dominating the rheology of the drilling mud. However, at bentonite content less than $6.3 \mathrm{wt}, \%$, the interaction between the silica nanoparticles and clay particles may be considered to be more pronounced under these conditions. This phenomenon may also explain the rapid rise in the characteristic time constant, $\beta_{3}$ up to bentonite content of 6.3 wt.\% (Figure 5(b)). The characteristic time scale for diffusion for the particles would decrease due to an increase in the interaction between particles dominated by the larger clay particles. Since the volume fraction of nanoparticles is kept constant, its interaction with clay particles will diminish with an increasing amount of clay particles. This effect is evident beyond the bentonite content of $6.3 \mathrm{wt} . \%$, where there is a decline in the characteristic time constant, $\beta_{3}$ (Figure 5(b)).

\subsection{The Effect of Nanoparticle Concentration at given Bentonite Content}

To study the effect of changing nanoparticle concentration at a given bentonite concentration, Figure 6 shows a plot of the tuning parameter and the characteristic time constant for a 13 wt. $\%$ drilling mud containing 0.2 to 0.6 vol.\% nanoparticles. The tuning parameter shows an increasing trend with nanoparticle concentration as evident in Figure 6(a). This simply shows the level of nanoparticle dispersion and the interaction associated with nanoparticles and clay particles. In order words, the tuning parameter captures the contribution of this dispersion and interaction to the overall shear stress profile of the drilling mud. This is consistent with the 
units of the parameter (in $\mathrm{Pa}$ ) which is similar to that of the shear stress. Additionally, the values of the tuning parameter may indicate the nature of nanoparticle dispersion in the mud solution. For low values of the tuning parameter reported in this work, this may indicate aggregation of the nanoparticles in solution. As such, the dispersion of the nanoparticles in the bentonite mud may not be nano-sized. However, there is need for more studies to be carried out on the tuning parameter for different nanoparticle type and different dispersion methods. The characteristic time constant, $\beta_{3}$ also showed an increasing trend with nanoparticle concentration (Figure 6(b)). This indicates that increasing amount of nanoparticles tend to interact with clay particles. Therefore, the characteristic timescale of diffusion would increase because there is enough nanoparticles in solution to interact with clay particles thereby altering the size and surface properties of both clay and nanoparticles. For the time constant, $\beta_{1}$, it can be observed from Table 3 that the values are low except at a nanoparticle concentration of 0.6 vol.\% and show no particular consistent trend. This stems from the fact that clay to clay particle interaction are reduced due to an increase in the amount of nanoparticles.

\subsection{Validating the Prediction of the Developed Model}

Statistical evaluation of the predictive capability of equation (19) was carried out using a response surface design methodology (RSM). The RSM allowed for the generation of a response surface model using the experimental data from the Nano-drilling mud. The procedure was carried out using a central composite design to generate a design matrix (Table 4) for the study of single, interaction and quadratic effects between the factors bentonite content $\left(\mathrm{X}_{1}\right)$ and nanoparticles, $\left(\mathrm{X}_{2}\right)$. MINITAB ${ }^{\circledR} 18$ (PA, USA) statistical software package was used for the design of experiments and statistical analysis. The response variable (Y) in this case was the rheological properties (plastic viscosity PV, yield point YP, and apparent viscosity AV) and was fitted to a second-order polynomial equation in (20): 
$Y:$ the predicted response; $\beta_{o i}:$ the intercept coefficient; $\beta_{i}$ : the linear coefficient; $\beta_{i i}:$ the squared coefficient; $\beta_{i j}$ : the interaction coefficient; $X_{i}$ : the coded independent variables; $X_{i} X_{j}$ : the interaction terms; $X_{i}^{2}$ : the quadratic terms. The statistical models obtained from regression analysis used in describing the response variable is given by the following secondorder polynomial equation as shown in equation (21) to (23):

$P V=0.0409-0.00918 X-0.0073 Y+0.000517 X^{2}+0.0104 Y^{2}+0.001884 X Y$

$\mathrm{AV}=0.1693-0.04072 \mathrm{X}-0.0047 \mathrm{Y}+0.002324 \mathrm{X}^{2}-0.00204 \mathrm{Y}^{2}+0.002752 \mathrm{XY}$

The obtained second-order response surface model above was used for the evaluation of the interaction effects on the rheological properties of the nano-drilling mud. However, before the analysis of interaction effects, there was a need to be certain that the developed surface model is capable of predicting the design matrix (Table 4). The coefficient of determination $\left(\mathrm{R}^{2}\right)$ for the obtained response surface models was $96.77,99.73$ and $99.81 \%$ respectively for (21), (22) and (23) respectively. This indicates that the obtained statistical model is suitable for the design matrix since it is higher than $70 \%$. More so, it indicated that surface model can account for greater than $95 \%$ variation in the design matrix while less than $5 \%$ cannot be accounted for by the models from (21) to (23). Similarly, other statistical tools were used in addition to the coefficient of determination to determine the suitability of the response surface model. The probability value (P-value) for the fitted model was less than 0.05 . This showed that the fitted model can confidently (>95\%) investigate and predict the design matrix of equation (19). Other statistical evaluation tools such as confidence and prediction intervals are also considered. Figure 7 shows the $95 \%$ confidence interval for equation (21). 
323 The tapered confidence interval connected with the model is suggestive of the accuracy of the

324

325

326

327

model in estimating the plastic viscosity for a definite set of the predictor variables (bentonite content and nanoparticles). Furthermore, in accessing the applicability of the proposed surface model, the uncertainty of predicting the value of a single future observation or a fixed number of multiple future observations based on the distribution of previous observations in the design matrix was evaluated. This was done using the prediction interval, which is the range that is likely to contain a single future response for a selected combination of variable settings. Figure 8 shows the $95 \%$ prediction interval for the plastic viscosity using equation (21). From equations (21) to (23), the interaction between bentonite clay particles and nanoparticles tend to be captured by the interaction term XY. This term has a significant effect on the rheological properties due to its probability value less than $5 \%$. In addition, the positive coefficients of the interaction term suggest the incremental effect this has on the rheology of the drilling mud. This further validates the trends reported with tuning parameter, $\beta_{o}$ and the characteristic time constant, $\beta_{3}$ of equation (19). The negative coefficients of the single terms $\mathrm{X}$ and $\mathrm{Y}$ suggests that individual particles cannot have an effect on the rheological properties.

\subsection{Shear Stress Limit Prediction and Experimental Validation.}

The shear erosive potential of the bentonite mud using equation (11) can be predicted according to equation (24).

$\lim _{\gamma \rightarrow \infty} \tau=\tau_{\lim }=\left[\tau_{0}+\frac{\beta_{2}}{\beta_{1}}\right]$

Where $\tau_{\text {lim }}(\mathrm{Pa})$ is the shear stress limit, which is a measure of the extent of shear stress tolerance of the bentonite mud. The shear stress limit was predicted using equation (20) for drilling mud containing 6, 9 and 11 wt.\% bentonite dispersed. The values for the shear stress 
limit predicted were $15.32,33.71$ and $63.8 \mathrm{~Pa}$ for 6,9 and 11 wt.\% bentonite respectively.

The experimental approach used in validating the predicted shear stress limit values was the

shear loading method. In this approach, a given shear rate $\left(1022 \mathrm{~s}^{-1}\right)$, which corresponds to viscometer for a period of 15 minutes. After a steady value for the dial reading (DR) was obtained, the applied shear rate was reduced to zero and the gelling or recovery (structural recovery) was noted for the same time period as the structural breakdown. The DR after the recovery was then noted and the process was repeated until the DR after a structural breakdown is constant. At this point, the bentonite mud has yielded and the DR was noted and compared with the prediction as derived from equation (24). The values estimated from the experiment compared to the predictions of the new model are summarized in Table 5. The plots of the shear stress versus time showing the shear loading-shear recovery of the bentonite mud is shown in Figure 9. The open markers refer to the point where the shear stress values remain constant and approximate the predicted values for shear stress limit by equation (24). Extending shearing time beyond what was applied in this study would result in a decrease in the values of the DR beyond the shear stress limit. This is indicative of the structural degradation of the bentonite mud and would result in an irreversible loss in viscosity.

\section{Conclusion and Recommendation}

This study was carried out to develop a new predictive approach to the modelling of the rheological behavior of nano-drilling muds. The Vipulanandan model was selected based on known conditions used in accessing the robustness and predictability of rheological models. In developing a rheological model for nano-drilling muds, the Vipulanandan model was modified using existing relationships. This includes relationships for the structural kinetics of cohesive sediment suspensions and that which describes the interparticle behavior of nanoparticles in aqueous solutions. A key advantage of this approach is that the shear stress is 
expressed as a function of nanoparticles parameters in a very simplified form and eliminates the need for a large number of tuning parameters. The significance of this outcome is that the impact of nanoparticles (as captured by size, material property and concentration) on the drilling mud rheology can be directly inferred during computational modelling using a single fitting parameter. This parameter, known as a tuning parameter in this work, helps to account for uncertainties surrounding nanoparticle interaction with clay particles. These uncertainties are known to arise from the changing surface properties of the nanoparticles and bentonite clay particles due to interactions. This approach helps to reduce the complexity of having a lot of fitting parameters and over parameterization associated with known models developed for nano-drilling muds. The modified Vipulanandan show better prediction for a $6.3 \mathrm{wt} \%$ mud with $\mathrm{R}^{2}$ of 0.999 compared to 0.962 for Power law and 0.991 for Bingham. However, the $\mathrm{R}^{2}$ value was the same with Herschel Buckley model but the RMSE value show better prediction for the Vipulanandan model with a value of $0.377 \mathrm{~Pa}$ compared to the $0.433 \mathrm{~Pa}$ for Herschel Buckley model. Validation of this was carried out by applying statistical tools the design matrix formed from the experimental analysis. The statistical evaluation further show the significance of these interactions between nanoparticles and clay particles and its impact on the rheological properties of the mud. Future works may consider incorporating the effects of temperature and salinity in the modified Vipulanandan model. This can be achieved by relating the associated time constants of the modified model with the characteristic equation for the rotational diffusion of particles. This approach would further reduce the uncertainty surrounding nanoparticle interaction with clay particles under extreme reservoir conditions.

\section{Nomenclature}

\section{Abbreviations}
DR
Dial Readings 


\section{Joumal Pre-proof}

397

PV

398

399

AV

400

$401 \tau_{0}$

402

403

$404 \tau_{p}$

$405 \tau_{\infty}$

$406 \mu_{\infty}$

$407 \phi$

$408 \quad d_{p}$

409

410

$411 \quad \mathrm{~A}_{\mathrm{o}}$

$412 \beta$

$413 \quad \mathrm{C}_{\mathrm{b}}$

$414 \quad C_{n}$

$415 \quad F_{v d w}$

$416 \quad \mathrm{H}$

$417 \quad \tau_{\mathrm{C}_{\mathrm{i}}}$

$418 \tau_{\lim }$

419 A

$420 \quad \mathrm{D}$

$421 \quad \beta_{0}$
Plastic Viscosity

Yield Point

Apparent Viscosity

Yield Point, Pa

Shear Stress, Pa

Shear Rate, $\mathbf{s}^{-1}$

Shear Stress due to Nanoparticles, Pa

Shear Stress measured at high Shear Rates, Pa

Viscosity at Infinite Shear Rate, Pas

Volume Fraction of Nanoparticles

Diameter of Nanoparticles, $\mathbf{n m}$

Radius of Nanoparticles, nm

Surface Area of Nanoparticles, $\mathbf{n m}^{\mathbf{2}}$

Haymaker's Constant, J

Parameter Constant in the Model of Gerogiorgis et al. (2017), s

Bentonite Content, wt.\%

Nanoparticle Concentration, vol.\%

Van der Waals Force, $\mathbf{N}$

Interparticle Distance between Nanoparticles, $\mathbf{n m}$

Shear Stress at a Reference Point (without nanoparticles), Pa

Shear Stress Limit, Pa

Parameter Constant in Vipulanandan Model, $[\text { Pas }]^{-\mathbf{1}}$

Parameter Constant in Vipulanandan Model, $\mathbf{P a}^{\mathbf{- 1}}$

Tuning Parameter in the Modified Vipulanandan Model, Pa 


\section{Joumal Pre-proof}

$422 \quad \beta_{1}$

$423 \quad \beta_{2}$

$424 \quad \beta_{3}$

$425 \quad \mathrm{~K}$

$426 \quad n$

$427 \quad \mu_{\mathrm{p}}$

428

$429 \gamma_{0}$

$430 \mathbf{s}^{-1}$

$431 \quad A_{t}$ and $B_{p} \quad$ Parameter Constants in Prandtl-Eyring Model.

$432 \lambda$

\section{Acknowledgement}

434 The authors would like to appreciate the management of Covenant University for providing 435 an enabling environment to carry out this research.

\section{$436 \quad$ Funding}

437 This research did not receive any specific grant from funding agencies in the public, 438 commercial, or not-for-profit sectors.

\section{Conflict of Interest}

440 The authors have no potential conflict of interest to declare regarding the publication of this 441 article. 
References

Abdo, J., \& Danish Haneef, M. (2012). Nano-Enhanced Drilling Fluids: Pioneering Approach to Overcome Uncompromising Drilling Problems. Journal of Energy Resources Technology, 134, 1-6.

Abu-Jdayil, B. (2011). Rheology of Sodium and Calcium Bentonite-Water Dispersions: Effect of Electrolytes and Aging Time. International Journal of Mineral Processing, 98, 208-213.

Afolabi, R. O., \& Yusuf, E. O. (2018). Nanotechnology and the Global Energy Demand: Challenges and Prospects for a Paradigm Shift in the Oil and Gas Industry. Journal of Petroleum Exploration and Production Technology, 1-19.

Afolabi, R. O., Orodu, O. D., \& Efeovbokhan, V. E. (2017a). Properties and application of Nigerian bentonite clay deposits for drilling mud formulation: Recent advances and future prospects. Applied Clay Science, 143, 39-49.

Afolabi, R. O., Orodu, O. D., Efeovbokhan, V. E., \& Rotimi, O. J. (2017b). Optimizing the rheological properties of silica nano-modified bentonite mud using overlaid contour plot and estimation of maximum or upper shear stress limit. Cogent Engineering, 4, 118.

Fan, H., Zhou, H., Meng, X., Gao, J., \& Wang, G. (2015). Accurate Prediction Model for Rheological Properties of Drilling Fluids at High Temperature and High Pressure Conditions. SPE/IATMI Asia Pacific Oil \& Gas Conference and Exhibition (pp. 1-14). Bali, Indonesia: Society of Petroleum Engineers.

Fazelabdolabadi, B., Khodadadi, A. A., \& Sedaghatzadeh, M. (2015). Thermal and Rheological Properties Improvement of Drilling Fluids using Functionalized Nanotubes. Applied Nanoscience, 5, 651-659. 
466

467

468

469

470

471

472

473

474

475

476

477

478

479

480

481

482

483

484

485

486

487

488

Gerogiorgis, D. I., Reilly, S., Vryzas, Z., \& Kelessidis, V. C. (2017). Experimentally Validated First-Principles Multivariate Modeling for Rheological Study and Design of Complex Drilling Nanofluid Systems. SPE/IADC Drilling Conference and Exhibition (pp. 1-11). Hague: Society of Petroleum Engineers.

Hoelscher, K. P., Stefano, G., Riley, M., \& Young, S. (2012). Application of Nanotechnology in Drilling Fluids. SPE International Oilfield Nanotechnology Conference (pp. 1-7). Noordwijk: Society of Petroleum Engineers.

Ismail, A. R., Aftab, A., Ibupoto, Z. H., \& Zolkifile, N. (2016). The Novel Approach for the Enhancement of Rheological Properties of Water-Based Drilling Fluids by using Multi-Walled Carbon Nanotube, Nanosilica and Glass Beads. Journal of Petroleum Science and Engineering, 139, 264-275.

Jung, C. M., Zhang, R., Chenevert, M., \& Sharma, M. (2013). High Performance WaterBased Mud using Nanoparticles for Shale Reservoirs. Unconventional Resources Technology Conference (pp. 1-7). Denver: Society of Petroleum Engineers.

Kelessidis, V. C., \& Maglione, R. (2008). Yield Stress of Water-Bentonite Dispersions. Colliods and Surfaces A: Physiochemical and Engineering Aspects, 318, 217-226.

Lee, E. J., Stefanus, C., \& Leong, Y. K. (2012). Structural Recovery Behaviour of Kaolin, Bentonite and K-Montmorillonite Slurries. Powder Technology, 223, 105-109.

Liberman, A., Mendez, N., Trogler, W. C. \& Kummel, A. C. (2014). Synthesis and surface functionalization of silica nanoparticles for nanomedicine. Surface Science Reports, $69(2-3), 132-158$.

Mahmoud, O., Nasr El-Din, H., Vryzas, Z., \& Kelessidis, V. (2016). Nanoparticle Based Drilling Fluids for Minimizing Formation Damage in HP/HT Applications. SPE 
International Conference and Exhibition on Formation Damage and Control (pp. 126). Louisiana: Society of Petroleum Engineers.

491

492

493

494

495

496

497

498

499

500

501

502

503

504

505

506

507

508

509

Reilly, S., Vryzas, Z., Kelessidis, V. C., \& Gerogiorgis, D. I. (2016). First Principles Rheological Modelling and Parameter Estimation for Nanoparticle Based Smart Drilling Fluids. European Symposium on Computer Aided Process Engineering (pp. 1-6). Portoroz: Elsevier B. V.

Toorman, E. A. (1997). Modelling the Thixotropic Behaviour of Dense Cohesive Sediment Suspensions. Rheologica Acta, 36(1), 56-65.

Vipulanandan, C., \& Mohammed, A. S. (2014). Hyperbolic Rheological Model with Shear Stress Limit for Acrylamide Polymer Modified Bentonite Drilling Muds. Journal of Petroleum Science and Engineering, 122, 38-47.

Vryzas, Z., \& Kelessidis, V. C. (2017). Nano-Based Drilling Fluids: A Review. Energies, 10, $1-34$.

Yoon, J., \& El-Mohtar. (2013). Dynamic Rheological Properties of Sodium Pyrophosphate Modified Bentonite Suspensions for Liquefaction Mitigation. Clays Clay Minerals, 61, 319-327.

Zakaria, M. F., Husein, M., \& Hareland, G. (2012). Novel nanoparticle-Based Drilling Fluid with Improved Characteristics. SPE International Oilfeild Nanotechnology Conference (pp. 1-6). Noordwijk: Society of Petroleum Engineers. 
Table 1: Rheological models and their predictive capabilities based on the conditions described in equations (1) to (4).

\begin{tabular}{|c|c|c|c|c|c|}
\hline Rheological Model & Equation $(\tau=\mathbf{f}(\dot{\gamma}))$ & $\lim _{\dot{\gamma} \rightarrow 0} \tau=\tau_{0}$ & $\frac{\mathrm{d} \tau}{\mathrm{d} \dot{\gamma}}>0$ & $\frac{\mathrm{d}^{2} \tau}{\mathrm{d} \dot{\gamma}^{2}}<\mathbf{0}$ & $\lim _{\dot{\gamma} \rightarrow \infty} \tau=\tau_{\max }$ \\
\hline Bingham Plastic & $\tau=\tau_{\mathrm{o}}+\mu_{\mathrm{p}} \dot{\gamma}$ & $\tau_{0}$ & $\mu_{\mathrm{p}}$ & 0 & $\infty$ \\
\hline Power Law & $\tau=\mathrm{K} \dot{\gamma}^{\mathrm{n}}$ & 0 & $\mathrm{Kn} \dot{\gamma}^{\mathrm{n}-1}$ & $\mathrm{Kn}(\mathrm{n}-1) \dot{\gamma}^{\mathrm{n}-2}$ & $\infty$ \\
\hline Herschel Buckley & $\tau=\tau_{\mathrm{o}}+\mathrm{K} \dot{\gamma}^{\mathrm{n}}$ & $\tau_{0}$ & $\mathrm{Kn} \dot{\gamma}^{\mathrm{n}-1}$ & $\mathrm{Kn}(\mathrm{n}-1) \dot{\gamma}^{\mathrm{n}-2}$ & $\infty$ \\
\hline Sisko & $\tau=a_{s} \dot{\gamma}+b_{s} \dot{\gamma}^{c_{s}}$ & 0 & $\mathrm{a}_{\mathrm{s}}+\mathrm{b}_{\mathrm{s}} \mathrm{c}_{\mathrm{s}} \dot{\gamma}^{\mathrm{c}_{\mathrm{s}}-1}$ & $\mathrm{~b}_{\mathrm{s}} \mathrm{c}_{\mathrm{s}}^{2} \dot{\gamma}^{\mathrm{c}_{\mathrm{s}}-2}$ & $\infty$ \\
\hline Robertson-Stiff & $\tau=K\left(\gamma_{o}+\dot{\gamma}\right)^{n}$ & $\mathrm{~K}\left(\gamma_{\mathrm{o}}\right)^{\mathrm{n}}$ & $\operatorname{Kn}\left(\gamma_{o}+\dot{\gamma}\right)^{n-1}$ & $\operatorname{Kn}(\mathrm{n}-1)\left(\gamma_{\mathrm{o}}+\dot{\gamma}\right)^{\mathrm{n}-2}$ & $\infty$ \\
\hline Prandtl-Eyring & $\tau=A_{t} \sinh ^{-1}\left(\frac{\dot{\gamma}}{B_{p}}\right)$ & 0 & $\frac{\mathrm{A}_{t}}{\sqrt{\frac{\mathrm{B}_{\mathrm{p}}{ }^{2}}{\mathrm{~B}^{2}}+1}}$ & $-\frac{\mathrm{A}_{\mathrm{t}} \dot{\gamma}}{\mathrm{B}_{\mathrm{p}}{ }^{3}\left(\frac{\dot{\gamma}^{2}}{\mathrm{~B}_{\mathrm{p}}{ }^{2}}+1\right)^{3 / 2}}$ & $\infty$ \\
\hline Vipulanandan & $\tau=\tau_{0}+\frac{\dot{\gamma}}{\mathrm{A}+\mathrm{D} \dot{\gamma}}$ & $\tau_{0}$ & $\frac{\mathrm{A}}{(\mathrm{A}+\mathrm{D} \dot{\gamma})^{2}}$ & $\frac{-2 \mathrm{AD}}{(\mathrm{A}+\mathrm{D} \dot{\gamma})^{3}}$ & $\tau_{0}+\frac{1}{D}$ \\
\hline
\end{tabular}


Table 2: Parameter constants of the modified Vipulanandan model for drilling mud with varying bentonite content containing 0.2 vol. $\%$ silica nanoparticles at $25^{\circ} \mathrm{C}$.

\begin{tabular}{ccccc}
\hline $\begin{array}{c}\text { Bentonite Content, } \boldsymbol{C}_{\boldsymbol{b}} \\
(\text { wt. \%) }\end{array}$ & $\begin{array}{c}\text { Tuning Parameter, } \\
\boldsymbol{\beta}_{\boldsymbol{o}}(\mathbf{P a})\end{array}$ & Time Constant, $\boldsymbol{\beta}_{\mathbf{1}}(\mathbf{s})$ & $\begin{array}{c}\text { Viscosity Parameter, } \boldsymbol{\beta}_{\mathbf{2}} \\
(\text { Pas) }\end{array}$ & Time Constant, $\boldsymbol{\beta}_{\mathbf{3}}(\mathbf{s})$ \\
\hline 0 & 0 & 0 & 0 & 0 \\
\hline 6.3 & 0.00014 & 0.00039 & 0.0063 & 0.0807 \\
\hline 13 & 0.00850 & 0.00090 & 0.0367 & 0.0096 \\
\hline 15 & 0.36640 & 0.00110 & 0.0820 & 0.0040 \\
\hline
\end{tabular}


Table 3: Parameter constants of the modified Vipulanandan model for $13 \mathrm{wt} . \%$ drilling mud containing 0.2 to 0.6 vol. $\%$ silica nanoparticles at $25^{0} \mathrm{C}$.

\begin{tabular}{ccccc}
\hline $\begin{array}{c}\text { Nanoparticle } \\
\text { Concentration }(\text { vol. \%) }\end{array}$ & $\begin{array}{c}\text { Tuning Parameter, } \\
\boldsymbol{\beta}_{\boldsymbol{o}}(\mathbf{P a})\end{array}$ & Time Constant, $\boldsymbol{\beta}_{\mathbf{1}}(\mathbf{s})$ & $\begin{array}{c}\text { Viscosity Parameter, } \boldsymbol{\beta}_{\mathbf{2}} \\
(\text { Pas) }\end{array}$ & Time Constant, $\boldsymbol{\beta}_{\mathbf{3}}(\mathbf{s})$ \\
\hline 0 & 0 & 0.0008 & 0.0361 & 0 \\
\hline 0.2 & 0.0085 & 0.0009 & 0.0367 & 0.0096 \\
\hline 0.4 & 0.2261 & 0.0006 & 0.0295 & 0.0318 \\
\hline 0.6 & 0.4209 & 0.0011 & 0.0410 & 0.0319 \\
\hline
\end{tabular}


Table 4: Experimental design matrix obtained analysed using the central composite design (CCD) and the predicted rheological properties of the nano-drilling mud.

\begin{tabular}{ccccc}
\hline Bentonite Content (wt.\%) & Silica Nanoparticles (vol.\%) & Plastic Viscosity (Pas) & Yield Point (Pa) & Apparent Viscosity (Pas) \\
\hline 6.3 & 0.0 & 0.0034 & 2.1449 & 0.0055 \\
\hline 6.3 & 0.2 & 0.0035 & 2.5535 & 0.0060 \\
\hline 6.3 & 0.4 & 0.0036 & 2.5535 & 0.0061 \\
\hline 6.3 & 0.6 & 0.0037 & 2.6046 & 0.0063 \\
\hline 13 & 0.0 & 0.0120 & 22.982 & 0.0350 \\
\hline 13 & 0.2 & 0.0130 & 28.089 & 0.0375 \\
\hline 13 & 0.4 & 0.0130 & 31.663 & 0.0405 \\
\hline 13 & 0.6 & 0.0130 & 62.816 & 0.0785 \\
\hline 15 & 0.0 & 0.0170 & 68.945 \\
\hline 15 & 0.2 & 0.0230 & 66.391 \\
\hline
\end{tabular}


Table 5: Comparison between experimental and predicted shear stress limit for bentonite mud

\begin{tabular}{ccc}
\hline $\begin{array}{c}\text { Bentonite } \\
(\text { wt. \%) }\end{array}$ & $\begin{array}{c}\text { Shear Stress Limit } \\
\text { (Experimental Approach) }\end{array}$ & $\begin{array}{c}\text { Shear Stress Limit } \\
\text { (Vipulanandan Model - Eqn 24) }\end{array}$ \\
\hline 6.0 & 15.32 & 14.25 \\
\hline 9.0 & 33.71 & 32.07 \\
\hline 11.0 & 63.84 & 62.24 \\
\hline
\end{tabular}




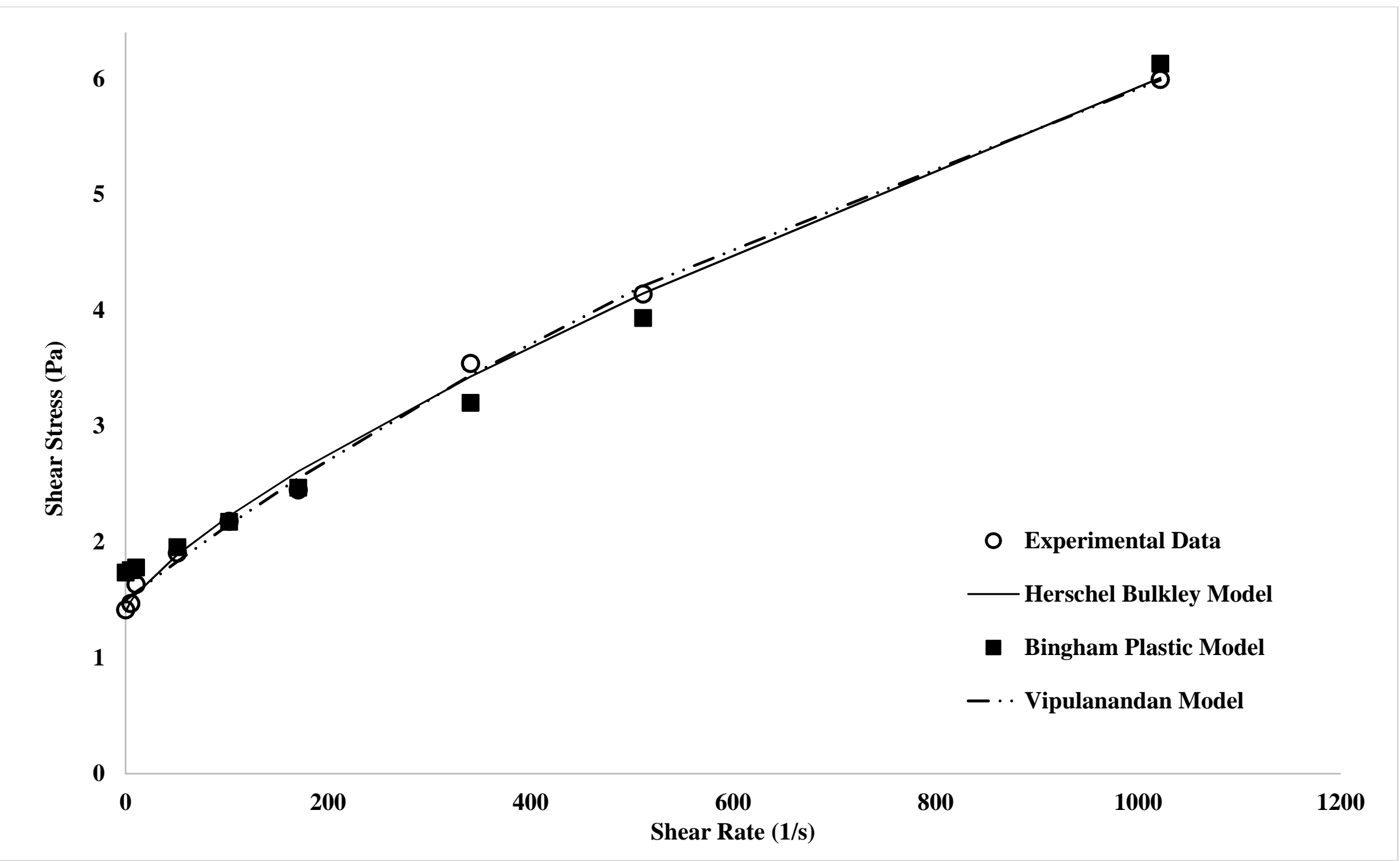

Figure 1: Rheological models applied to viscometeric data obtained for $6.3 \mathrm{wt} . \%$ bentonite mud at $25^{\circ} \mathrm{C}$ 


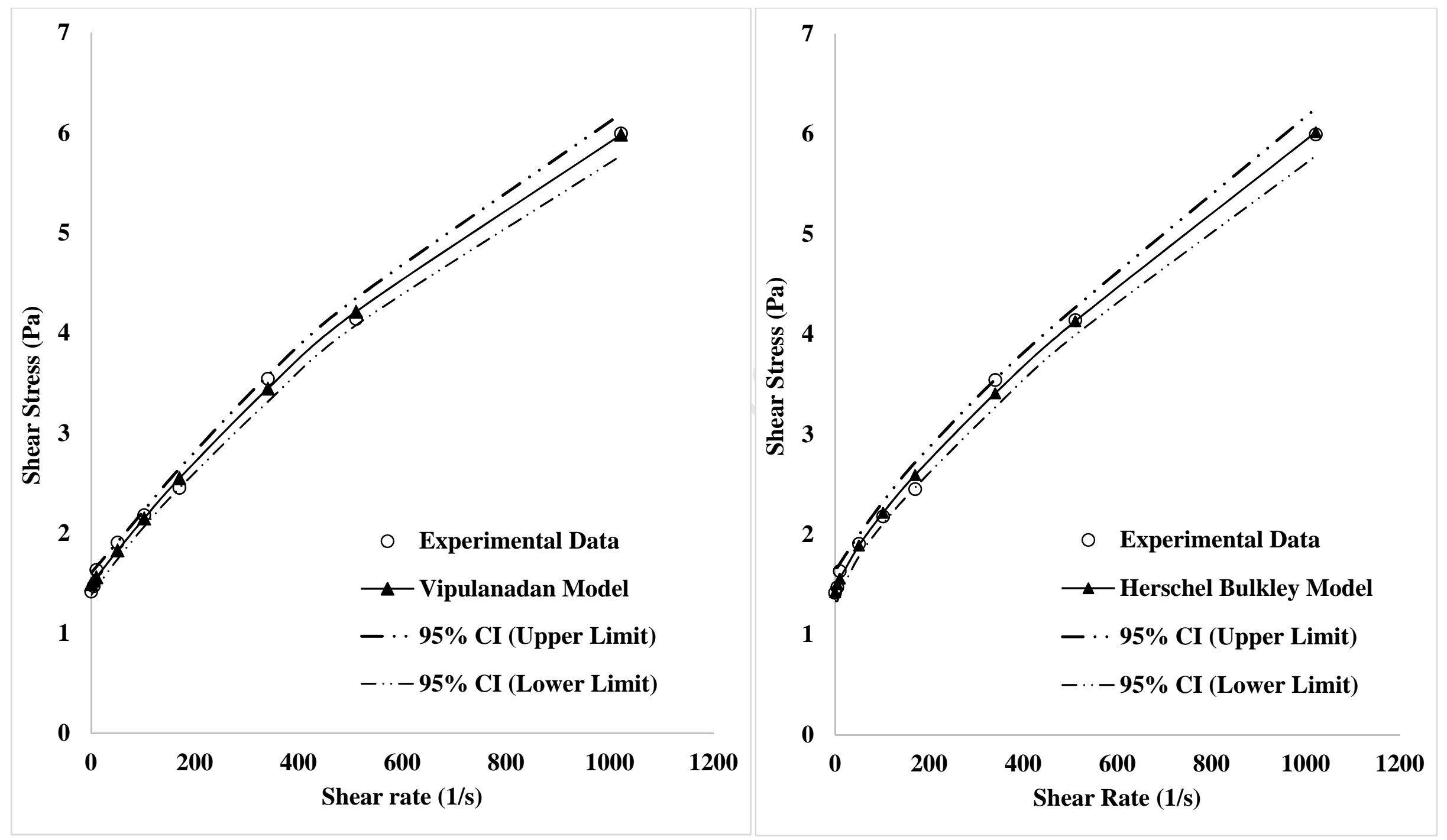

Figure 2: The prediction for Vipulanandan and Herschel Bulkley models at 95\% confidence interval (CI) using viscometric data obtained for 6 wt.\% bentonite mud at a temperature of $25^{\circ} \mathrm{C}$ 

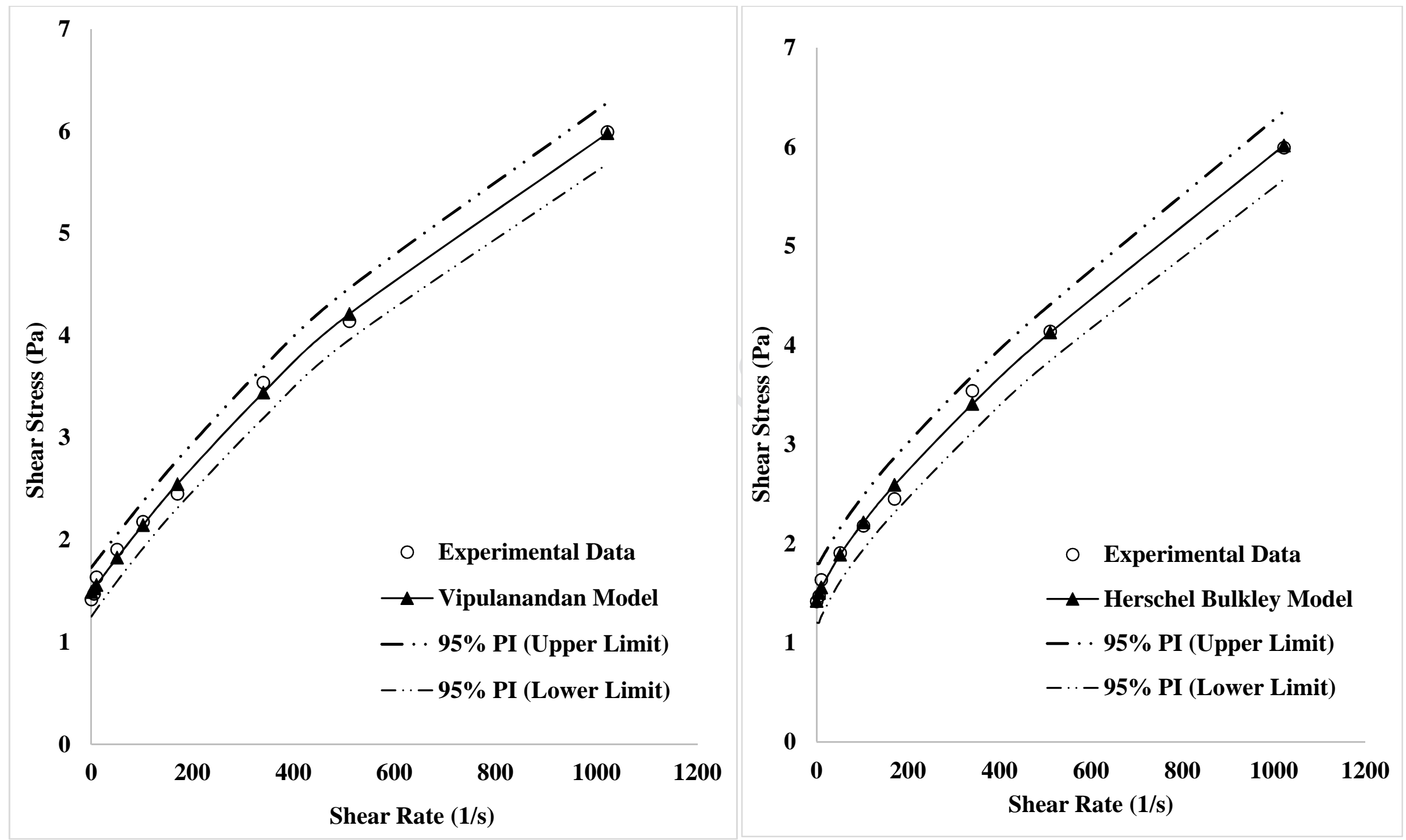

Figure 3: The prediction for Vipulanandan and Herschel Bulkley models at 95\% prediction interval (PI) using viscometric data obtained for 6.3 wt.\% bentonite mud at a temperature of $25^{\circ} \mathrm{C}$ 


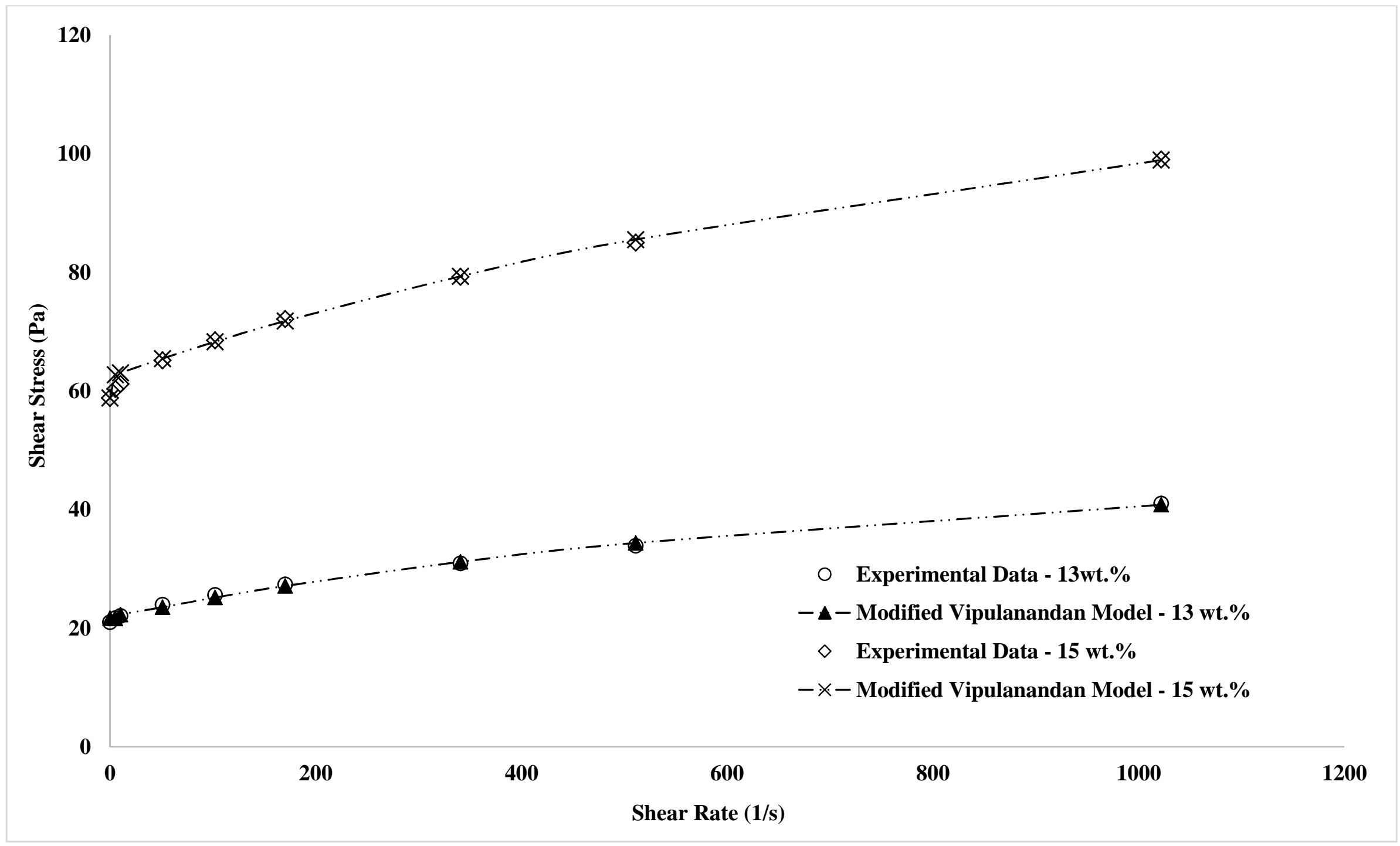

Figure 4: Fitted modified Vipulanandan model to rheological data for drilling mud containing 13, 15 wt.\% bentonite clay and 0.2 vol.\% silica nanoparticles at $25^{\circ} \mathrm{C}$ 


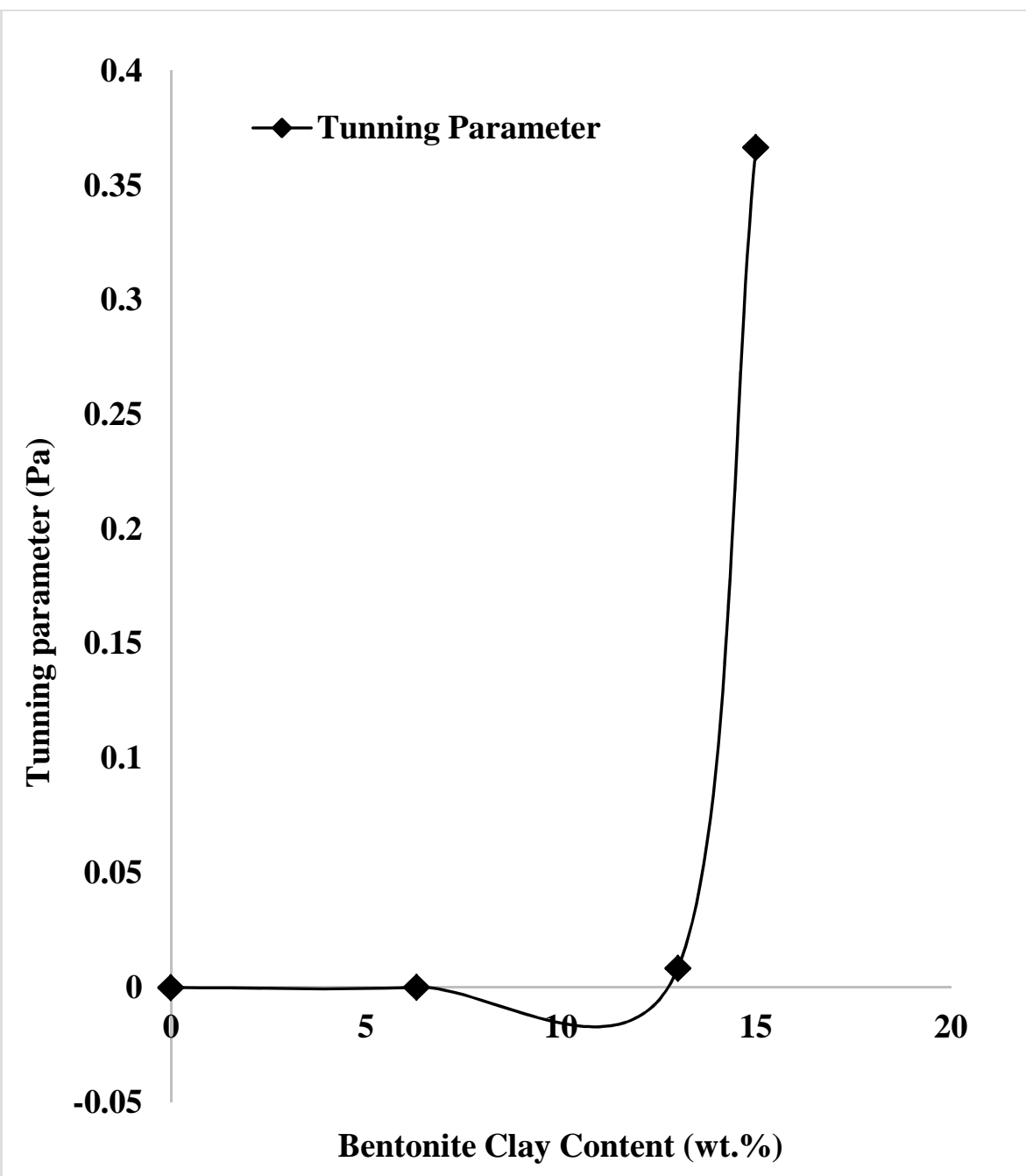

(a)

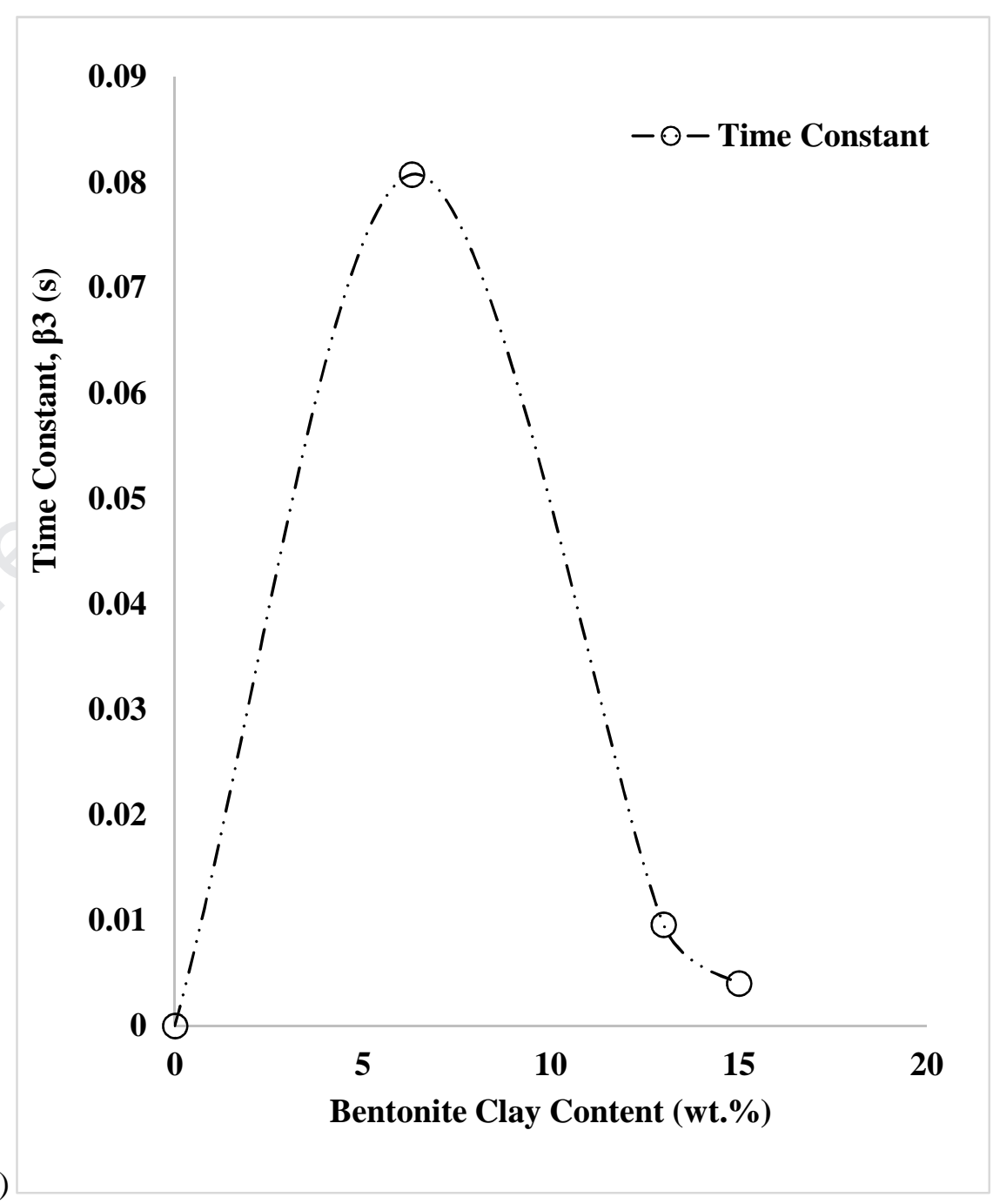

Figure 5: Effect of bentonite content on (a) the tuning parameter, $\beta_{0}$ and (b) the time constant, $\beta_{3}$ for a drilling mud containing 0.2 vol.\% silica nanoparticles at $25^{\circ} \mathrm{C}$. 


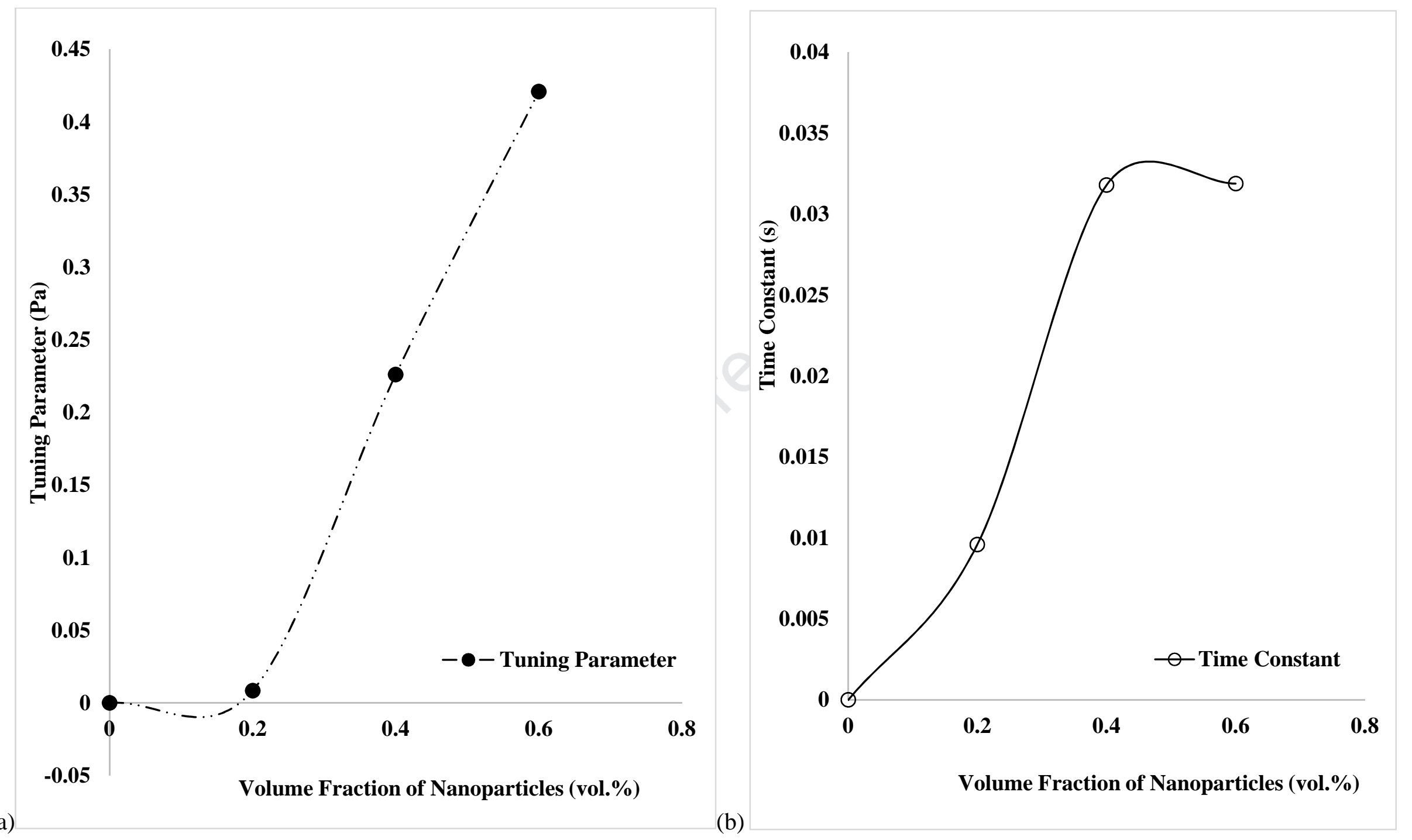

Figure 6: Effect of volume fraction of nanoparticles on (a) the tuning parameter, $\beta_{0}$ and $(b)$ the time constant, $\beta_{3}$ for a drilling mud containing $13 \mathrm{wt} . \%$ bentonite clay at $25^{\circ} \mathrm{C}$. 


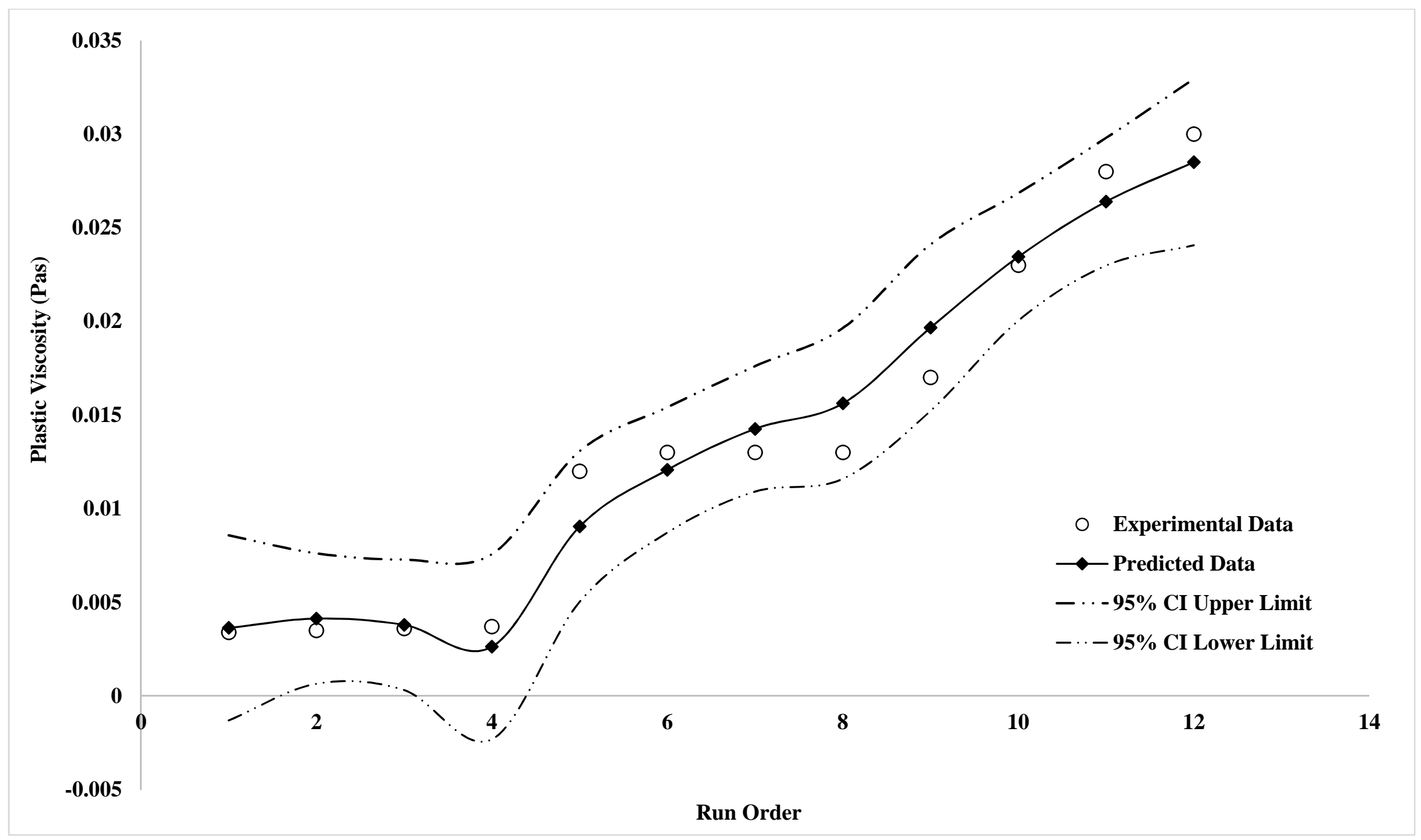

Figure 7: The 95\% confidence interval for the statistical model obtained for plastic viscosity in (21) using the experimental design matric of Table 4. 


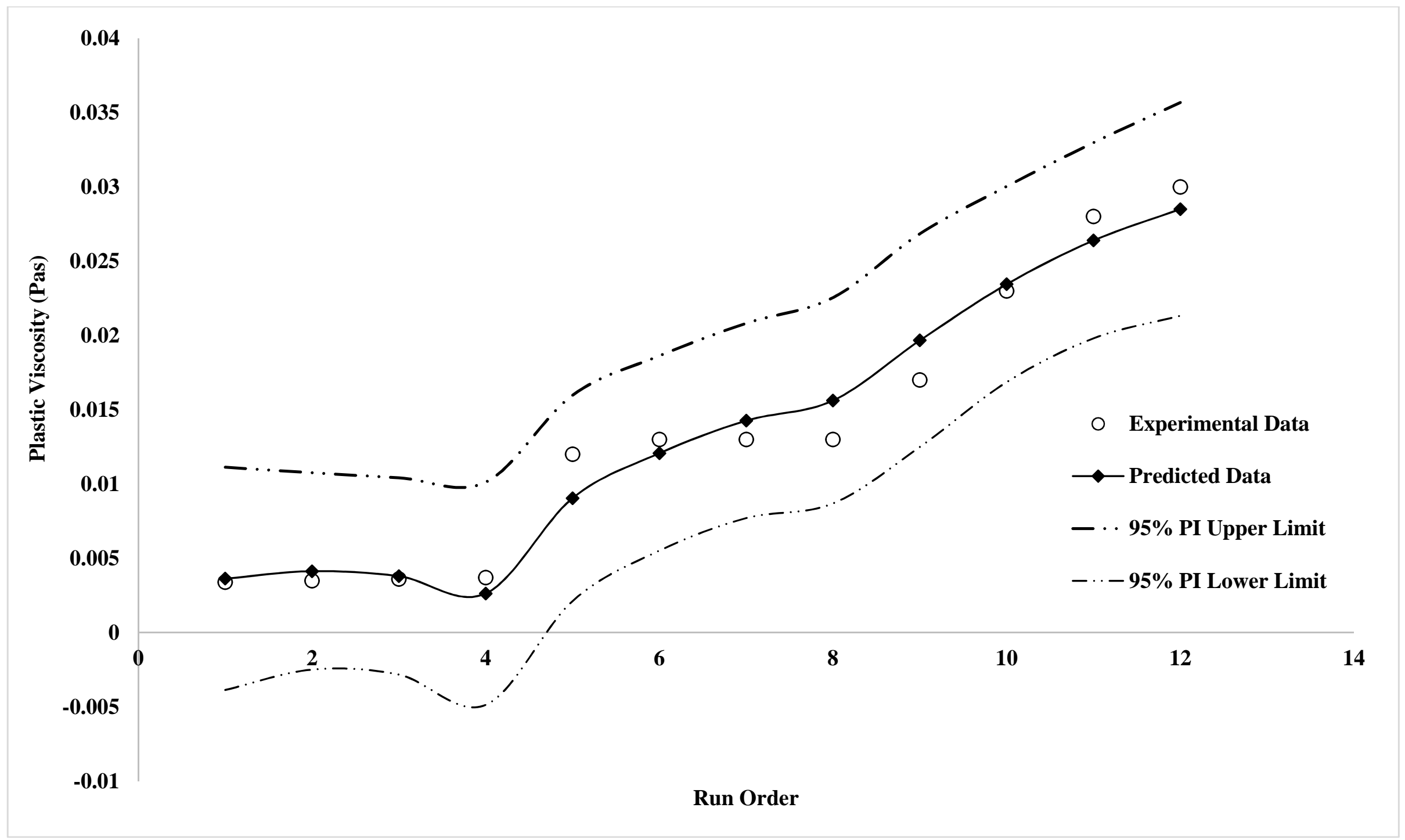

Figure 8: The 95\% prediction interval (PI) for the statistical model obtained for plastic viscosity in (21) using the experimental design matric of Table 4. 


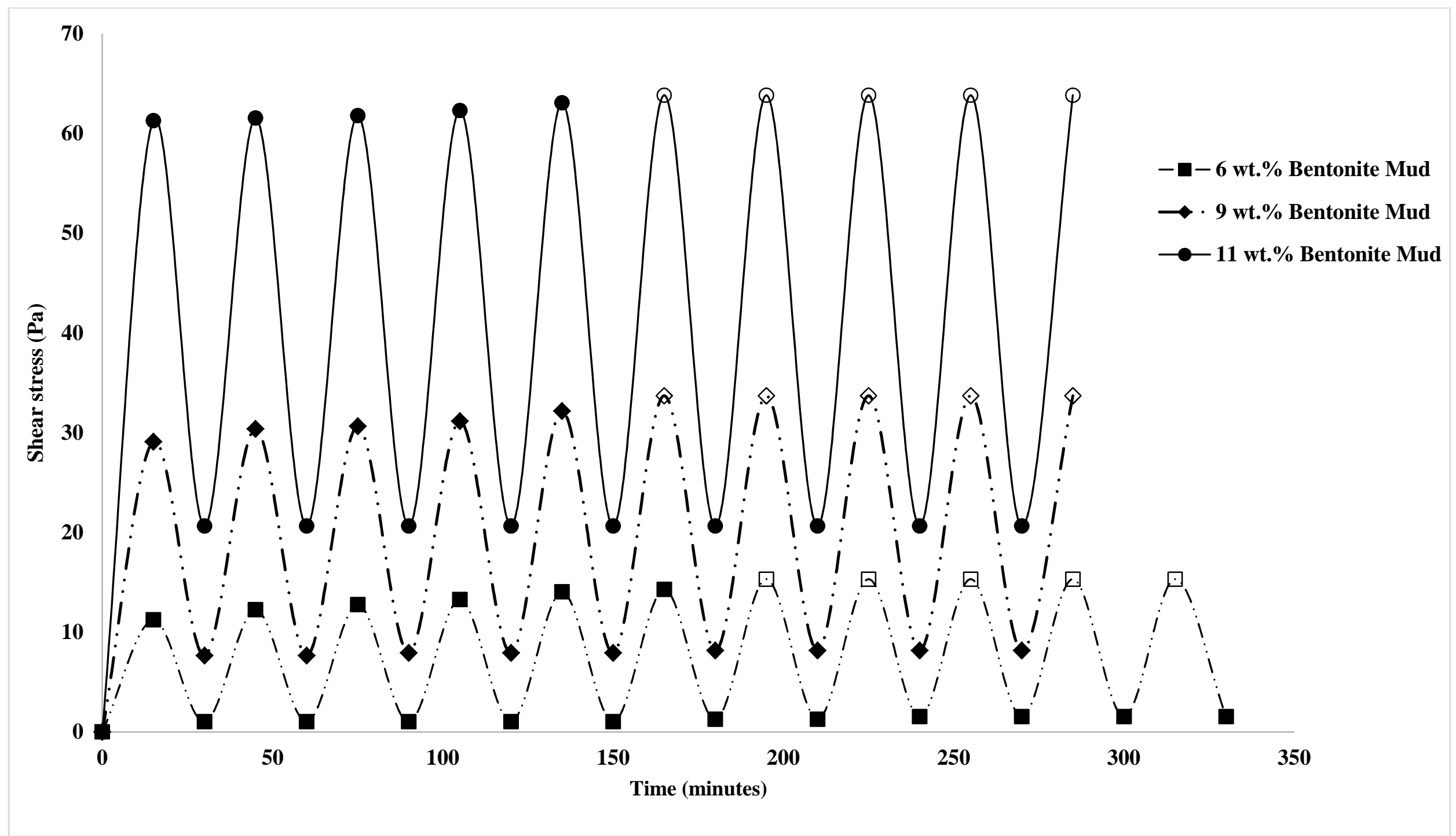

Figure 9: Experimental validation results for shear stress limit prediction for 6, 9 and 11 wt.\% bentonite mud at shear rate of $1022 s^{-1}$ and temperature of $25{ }^{\circ} \mathrm{C}$. The open marker (no fill) corresponds to the constant shear stress values, which approximates the shear stress limit predicted by equation (24). 


\section{Highlights}

- The Vipulanandan rheological model was modified to account for nanoparticle effect.

- This novel approach ensured few fitting parameter compared to other nano-models.

- This ensured that the complexity of the computational modelling was simplified.

- A tuning parameter was used to account for the uncertainty arising from nanoparticle clay particle interaction. 